\title{
Evaluation of chemiluminescence method for the analysis of plasma homocysteine and comparison with HPLC method in children samples
}

\author{
Avaliação do método de quimioluminescência na análise de homocisteína plasmática e sua \\ comparação com o método de HPLC em amostras de crianças
}

Thais Moura Gascón ${ }^{1}$, Fernanda Schindler ${ }^{2}$, Claudia Giorgia Bronzatti de Oliveira ${ }^{3}$, Fabiola Isabel Suano Souza ${ }^{4}$, Sonia Hix ${ }^{5}$, Roseli Oselka Sacardo Sarni ${ }^{6}$, Ana Paula Arantes Bacan 7 , Vania D’Almeida ${ }^{8}$, Auro del Giglio Fernando Luiz Affonso Fonseca ${ }^{10}$

\begin{abstract}
Objective: To compare the results for homocysteine concentration using chemiluminescence and HPLC methods in samples from school-age children. In addition, to determine the reference values for patients of this age group and assess the real prognostic value of homocysteine in healthy children. Methods: A prospective observational study was undertaken to determine plasma levels of homocysteine using two different assays, HPLC and chemiluminescence, in 185 samples from school-age children living in Santo Andre, with no chronic or inflammatory diseases, and absence of pubertal development. Results: The results were presented in percentiles and reference values were determined within this age group (7-9 years old). Homocysteine concentration ranged from 2.0 to $9.9 \mu \mathrm{mol} / \mathrm{l}(\mathrm{r}=0.821$ and $\mathrm{p}<0.001$ ). Conclusions: It was verified that chemiluminescence is comparable to HPLC when both techniques are used to detect homocysteine in school-age children. There is an important correlation between both methods, which allows investigation of this amino acid as a risk factor for heart diseases.
\end{abstract}

Keywords: Homocysteine; Chromatography, high pressure liquid; Chemiluminescences measurements

\section{RESUMO}

Objetivo: Comparar os resultados da concentração de homocisteína usando os métodos de quimioluminescência e HPLC em amostras de crianças escolares. Determinar os valores de referência desse grupo etário e avaliar o valor prognóstico real da homocisteína em crianças saudáveis. Métodos: Um estudo prospectivo observacional foi executado para determinar os níveis de homocisteína usando dois ensaios diversos, o HPLC e a quimioluminescência, em 185 amostras de crianças em idade escolar moradoras da cidade de Santo André, que não apresentassem doenças crônicas ou inflamatórias, na ausência de desenvolvimento puberal. Resultados: 0s resultados foram apresentados em percentis e os valores de referência foram determinados para esse grupo etário (7-9 anos). As concentrações de homocisteína variaram de 2,0 a 9,9 $\mu \mathrm{mol} / \mathrm{l}(\mathrm{r}=0,821$ e $\mathrm{p}<0,001)$. Conclusões: Verificamos que o método da quimioluminescência é

\footnotetext{
Study carried out at Faculdade de Medicina do ABC - FMABC, Santo André (SP), Brazil.

Graduate student in Health Sciences of Faculdade de Medicina do ABC - FMABC, Santo André (SP), Brazil.

${ }^{2}$ Master's degree in Sciences of Faculdade de Medicina do ABC - FMABC, Santo André (SP), Brazil.

${ }^{3}$ Master's degree in Sciences of Faculdade de Medicina do ABC - FMABC, Santo André (SP), Brazil.

${ }^{4} \mathrm{PhD}$; Professor at Department of Pediatrics of Faculdade de Medicina do ABC - FMABC, Santo André (SP), Brazil.

${ }^{5}$ PhD; Assistant Professor at Department of Biochemistry of Faculdade de Medicina do ABC - FMABC, Santo André (SP), Brazil.

${ }^{6} \mathrm{PhD}$; Professor at Department of Pediatrics of Faculdade de Medicina do ABC - FMABC, Santo André (SP), Brazil.

${ }^{7}$ Medical student at Faculdade de Medicina do ABC - FMABC, Santo André (SP), Brazil.

${ }^{8}$ Post-doctorate degree; Adjunct Professor at the Universidade Federal de São Paulo - UNIFESP, São Paulo (SP), Brazil.

${ }^{9}$ Post-doctorate degree; Full Professor at Department of Hematology and Oncology of Faculdade de Medicina do ABC - FMABC, Santo André (SP), Brazil; Oncology Sector of Hospital Israelita Albert Einstein - HIAE, São Paulo (SP), Brazil.

${ }^{10}$ Post-doctorate degree; Professor at Department of Hematology and Oncology of Faculdade de Medicina do ABC - FMABC; Adjunct Professor at Universidade Federal de São Paulo - UNIFESP, Diadema, (SP), Brazil.

Corresponding author: Fernando Luiz Affonso Fonseca - Laboratório de Análises Clínicas da Faculdade de Medicina do ABC - Avenida Príncipe de Gales, 821 - Príncipe de Gales - CEP 09060-650 Santo André (SP), Brazil - Tel.: 11 4993-5488-e-mail: fon_fonseca@yahoo.com.br 
comparável ao método HPLC quando as técnicas são usadas para detectar a homocisteína em crianças em idade escolar. Houve importante correlação entre os dois métodos, o que permite a investigação desse aminoácido como um fator de risco para doenças cardíacas.

Descritores: Homocisteína; Cromatografia líquida de alta pressão; Medições quimioluminescentes

\section{INTRODUCTION}

Homocysteine is a sulfur-containing amino acid found at the crossroads of two metabolic pathways: remethylation to form methionine, and transsulfuration, resulting in irreversible cystathionine ${ }^{(1)}$.

Homocysteine is derived from dietary methionine and is an intermediate metabolite in the biosynthetic pathway which converts methionine into cysteine. Therefore, cysteine is not an essential amino acid in humans, as it can be synthesized from methionine, via transsulfuration process. Dietary methionine is converted into S-adenosylmethionine (SAM) by the enzyme methionine-adenosyltransferase (MAT), which forms high energy disulfide bonds between carbon-5' of ATP ribose and methionine sulfur. A small amount of SAM is used for polyamine synthesis, and most of it donates its methyl group to other compounds, such as creatine, DNA and RNA. Thus, $\mathrm{SAM}$ is metabolized to S-adenosylhomocysteine, which, in turn, is hydrolyzed in homocysteine and $\operatorname{adenosine}^{(2)}$.

The intracellular and plasma levels of homocysteine are normalized with the activity of enzymes that participate in its metabolic pathway, as well as appropriate levels of vitamin B12 and, mainly, folate ${ }^{(2)}$.

Several diseases and situations have been associated with higher levels of homocysteine, for example chronic heart failure $^{(3)}$, effects of vascular diseases ${ }^{(4)}$ besides oxidative stress $^{(5)}$, type 1 diabetes ${ }^{(6)}$, obesity(7) and homocystinuria $^{(8)}$. However, it is not very safe to say if these changes are the cause or the consequences of primary diseases. In some cases, however, this situation seems clearer, as in neural tube defects and heart diseases $^{(9)}$.

Among a number of methods to analyze and determine homocysteine, HPLC (high performance liquid chromatography) is considered to be the method of reference (gold standard). Nevertheless, when comparing the cost/benefit ratio, its use may be impaired, for being expensive and depending on the analyst skills to be performed. However, other laboratory techniques have already been described and can be used with no implications in quality and results of analysis. One of these techniques is chemiluminescence and, when compared to the reference method, it does not constrict the clinical analysis of results and may be more advantageous regarding its cost/benefit ratio and easy-to-use features ${ }^{(10)}$.

\section{OBJECTIVES}

The aim of this study was to compare the results for homocysteine concentration using chemiluminescence and HPLC methods in samples comprised of schoolaged children. In addition, the reference values for patients in this age group were determined and the real prognostic value of homocysteine in healthy children was assessed.

\section{METHODS}

After being approved by the Institutional Review Board, this prospective observational study was carried out between 2006 and 2008. The study group consisted of 185 prepuberal children, aged 7-9 years, enrolled at a public school in the city of Santo André, State of São Paulo, Brazil.

Children with any chronic, genetic, congenital or acquired immunodeficiency and infectious or inflammatory disease were excluded. We also excluded those who were on corticosteroids and who had been admitted to hospital in the past three months.

Blood samples were collected to determine the plasma levels of homocysteine, using both HPLC e chemiluminescence assays. We collected 185 samples by venipuncture, after fasting for at least four hours.

The 10-ml samples were separated into two test tubes with EDTA (ethylenediaminetetraacetic acid), which were kept under refrigeration until centrifugation for 6-8 minutes, at $3000 \mathrm{rpm}$. The obtained plasma samples were stored until analysis.

The samples were analyzed using a Shimadzu HPLC (SIL -10 Dvp) coupled with fluorimetric detection (RF10 AXL) and isocratic elution at the Inborn Errors of Metabolism Laboratory, Center for Medical Genetics, Universidade Federal de São Paulo (UNIFESP). The chromatographic separation used Phenomenex Prodigy ODS2 with a column $(3.2 \times 150 \mathrm{~mm}, 5-\mu$ microparticles $)$. Fluorescence-separated compounds were captured by the detector adjusted for excitation of $385 \mathrm{~nm}$ and an emission of $515 \mathrm{~nm}$. Total homocysteine was estimated using a calibration curve with known amounts of homocysteine ${ }^{(11)}$.

The immunoenzymatic assay was performed using automated chemiluminescence apparatus model Immulite 2000 at the Laboratory of Clinical Analysis of Faculdade de Medicina do ABC (FMABC). 
At the beginning of the chemiluminescense routine analysis in this equipment, the adjustments were performed in four replicates, following the manufacturer's recommendations.

In order to compare the results in both techniques, we measured 20 samples with hyperhomocysteinuria (well-known concentrations determined by HPLC), which were measured again and determined by chemiluminescence.

We used the SPSS 18.0 software to calculate Pearson's correlation coefficient, thus estimating sensitivity and specificity, and determining the Receiver Operating Characteristic (ROC) curve. However, when analyzing hyperhomocysteinaemia, we used Spearman's correlation coefficient.

\section{RESULTS}

The $50^{\text {th }}$ percentiles of reference values were presented for both techniques: HPLC and chemiluminescence.

The percentile values for HPLC analysis demonstrate that $50 \%$ of 7 -year-old patients presented values below $5.3 \mu \mathrm{mol} / \mathrm{l}$ whereas the 8 and 9-year-old children presented values below $5.4 \mu \mathrm{mol} / \mathrm{l}$ and $5.9 \mu \mathrm{mol} / \mathrm{l}$, respectively. For the chemiluminescence assay, the following values were found: $3.2 \mu \mathrm{mol} / 1 ; 3.3 \mu \mathrm{mol} / \mathrm{l}$; and $3.6 \mu \mathrm{mol} / 1$. In children aged between 7 and 9 years, the minimum value was $2.0 \mu \mathrm{mol} / 1$, the maximum was 9.9 $\mu \mathrm{mol} / 1$, and the mean value was $3.6 \mu \mathrm{mol} / \mathrm{l}$. Consequently, the verified reference values were between $2.0 \mu \mathrm{mol} / \mathrm{l}$ to $9.9 \mu \mathrm{mol} / \mathrm{l}$ (Table 1).

Table 1. Percentile values, for age, HPLC and chemiluminescence techniques

\begin{tabular}{lcccccc}
\hline \multirow{2}{*}{ Percentile } & \multicolumn{3}{c}{ HPLC } & \multicolumn{4}{c}{ Chemiluminescence } \\
\cline { 2 - 7 } & $\mathbf{7}$ years & $\mathbf{8}$ years & $\mathbf{9}$ years & $\mathbf{7}$ years & $\mathbf{8}$ years & $\mathbf{9}$ years \\
\hline 99.0 & 12.317 & 11.320 & 13.033 & 9.9 & 8.4 & 9.3 \\
95.0 & 8.916 & 9.010 & 8.646 & 5.6 & 5.5 & 6.1 \\
90.0 & 7.613 & 7.407 & 8.098 & 5.3 & 5.0 & 5.4 \\
75.0 & 6.689 & 6.270 & 6.610 & 4.2 & 4.1 & 4.2 \\
50.0 & 5.312 & 5.410 & 5.860 & 3.2 & 3.3 & 3.6 \\
25.0 & 4.189 & 4.716 & 4.953 & 2.3 & 2.6 & 3.0 \\
10.0 & 3.634 & 3.917 & 4.443 & 2.0 & 2.0 & 2.6 \\
5.0 & 3.119 & 2.857 & 4.091 & 2.0 & 2.0 & 2.4 \\
1.0 & 2.497 & 0.000 & 3.598 & 2.0 & 2.0 & 2.0 \\
\hline
\end{tabular}

Using linear regression analysis in both techniques, HPLC and chemiluminescence, a significant correlation between them was obtained $(\mathrm{r}=0.821, \mathrm{p}<0.001)$, as shown in Figure 1.

The values obtained from HPLC and chemiluminescence analyses show a positive and

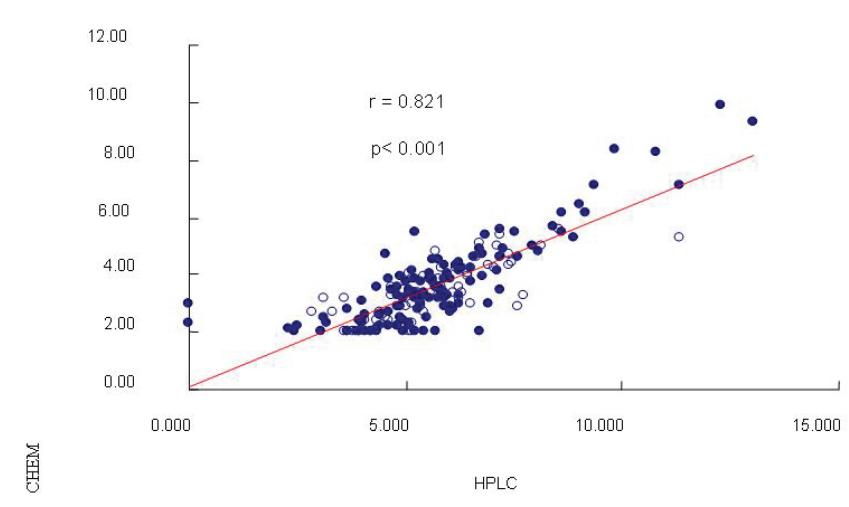

Figure 1. Correlation between chemiluminescence and HPLC

significant correlation. Thus, when the concentration obtained via HPLC increases, the level via chemiluminescence also rises.

Therefore, we found that the sensitivity for this method is $87.5 \%$, the specificity is $97.0 \%$, with positive and negative predictive values of $98.8 \%$ and $96.2 \%$, respectively (Figure 2).

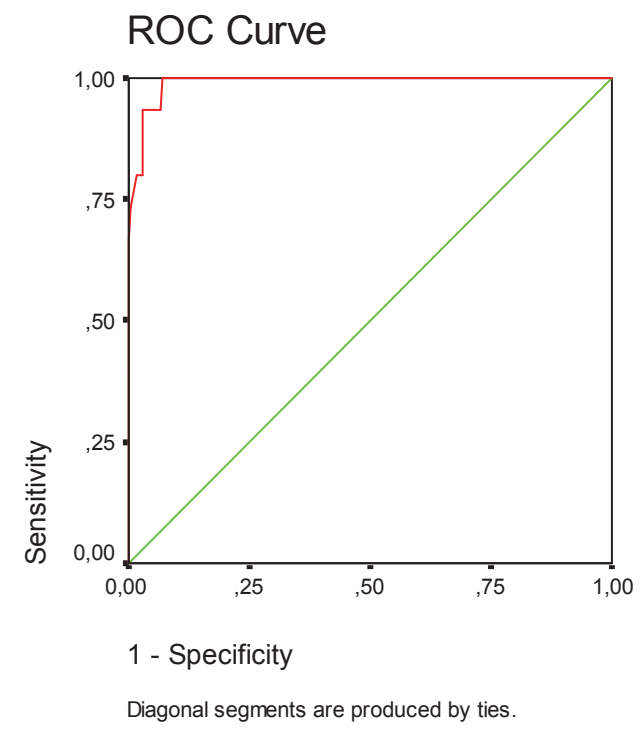

Figure 2. ROC curve (sensitivity and specificity)

The results for hyperhomocysteinemia measured by chemiluminescence assay showed, through Spearman's coefficient, that there was a positive and significant correlation between both techniques $(\mathrm{r}=0.889$ and $\mathrm{p}$ $<0.001)$.

Using chemiluminescence, urine homocysteine samples presented a mean value of 167.9, a median value of 187.5, and minimum and maximum values of 4.7 and 505.0. With the HPLC technique, the mean value was 148.3 , the median value was 134.8 , and the minimum and maximum values were 333.8 (Figure 3 ). 


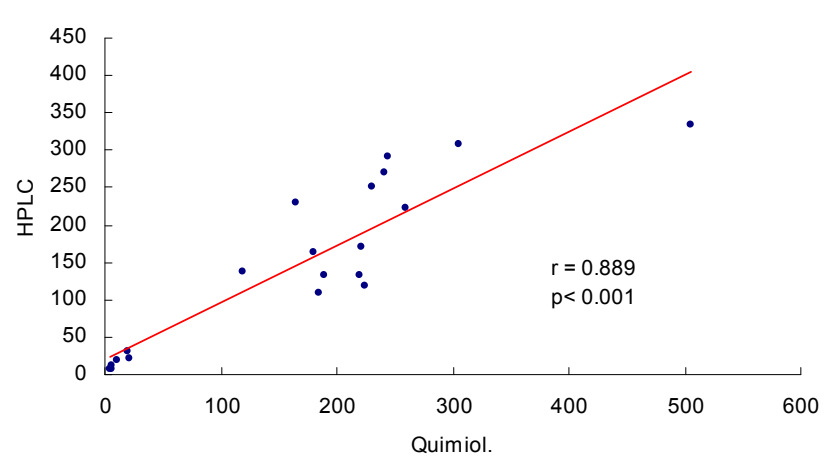

Figure 3. Correlation between both techniques to measure hyperhomocysteinemia

\section{DISCUSSION}

In the present study, we demonstrated that the use of chemiluminescence technique to measure plasma homocysteine presents a positive and significant correlation, assessing the real prognostic value of homocysteine levels in healthy children. The results suggest that it is possible to use chemiluminescence technique as a diagnostic method for the metabolic disorder involving homocysteine.

In most researches, the concern is to appraise the total concentration of homocysteine in adults, in order to establish a reference value to help prevent or even to define a clinical prognosis for cardiovascular risk.

For the time being, this standard quantification for children at preschool age has not been completely elucidated, as demonstrated by a study carried out with Belgian children, which determined reference values in three age groups, measured in both sexes, using HPLC technique, as follows: 5 to 9 years $(6.21 \mu \mathrm{mol} / \mathrm{l}), 10$ to 14 years $(7.09 \mu \mathrm{mol} / \mathrm{l})$ and 15 to 19 years $(8.84 \mu \mathrm{mol} / \mathrm{l})$. An increase in homocysteine levels when approaching adulthood is clear distinguishable, probably caused by effects of hormones during puberty ${ }^{(12)}$.

Our results, when compared to the study mentioned above, both of them concerning young populations, indicate that plasma levels of homocysteine found are consistent, even though the methodology used is chemiluminescence assay instead of HPLC.

In this article, the authors cite other studies that provide guidelines to assess homocysteine concentration averages among young subjects. Vilaseca et al. analyzed homocysteine concentration in children aged 2 to 10 years $(5.8 \mu \mathrm{mol} / \mathrm{l}), 11$ to 15 years $(6.6 \mu \mathrm{mol} / \mathrm{l})$, and 16 to 18 years $(8.1 \mu \mathrm{mol} / \mathrm{l})^{(12)}$.

The National Institutes of Health performed a study on homocysteine levels in a representative sample of American adolescents and adults. Three samples were collected in different moments related to folate fortification. The analytical method used to determine homocysteine was modified during the course of the study. They started with HPLC (1991-1999) and completed the analysis using the immunoassay analyzer Abbott IIMX $^{\circledR}$ (1999-2001) and Abbott AxSYM ${ }^{\circledR}$ (20022004). SAS and SUDAAN statistical software was used, proving that the use of different analytical techniques did not involve detrimental changes in the final analysis of the results, as our results demonstrated ${ }^{(13)}$.

The laboratory techniques to quantify homocysteine (HPLC) are costly, hindering routine analysis, mainly when concerning the elucidation of results from Public Health Services users.

Thus, plasma homocysteine analysis would be less time-consuming, reduce expenditure with reagents and provide assistance to the majority of population in doing these tests.

There are few studies published on homocysteine determination in healthy or unhealthy children, but other analytical techniques had already been described and can be used without interfering in quality and results.

According to Stauffenberg, the chemiluminescence technique, when compared to the reference method (HPLC), does not impair the clinical evaluation of homocysteine concentration and can be even more favorable concerning its cost/benefit ratio and easiness to operate ${ }^{(14)}$.

Notwithstanding, homocysteine is a risk factor, its determination is unusual, maybe because of the high costs of HPLC technique. Thus, our results suggest that it is possible to effectively measure it using chemiluminescence technique, as the samples presenting homocysteinuria were statistically significant when we compared both methods.

\section{CONCLUSIONS}

Our results proved that the determination of plasma homocysteine levels using chemiluminescence could be used as a routine assay in samples within the reference values, as well as in samples presenting high levels of homocysteine.

\section{REFERENCES}

1. Verhoef P, Steenge RG, Boelsma E, Vliet T, Olthof RM, Katan BM. Dietary serine and cystine attenuate the homocysteine - raising effect of dietary methionine: a randomized crossover trial in humans. Am J Clin Nutr. 2004;80(3):674-9.

2. Mudd SH, Levy HL, Skovby F. Disorders of transsulfuration. In: Scriver CR, Beaudet AL, Sly WS, Valle D, editors. The metabolic basis of inherited disease. 3th ed. New York: McGraw Hill; 1995. p. 1887-912.

3. Herrman M, Shomal O, Hubner U, Bohm M, Herrman W. A Review of homocysteine and heart failure. Eur J Heart Failure. 2006;8(6):571-6. 
4. Bouschey CJ, Beresford SA, Omeni GS, Motulsky AG. A quantitative assessment of plasma homocysteine as a risk fator for vascular disease. Probable benefits of increasing folic acid intakes. JAMA.1995;274(13):1049-57.

5. Weiss N. Mechanisms of Increased Vascular Oxidant Stress in Hyperhomocysteinemia and Its Impact on Endothelial Function. Cur Drug Metab. 2005;6(1):27-36.

6. Meloni FG, Tonolo CG, Zuppi C. Hyper-homocysteinemia is not a main feature of juvenile uncomplicated type 1 diabetes. J Atheroscl Thromb. 2004;12(1):14-20.

7. Oshaug A, Brigge KH, Refsum H. Diet, an independent determinant for plasma total homocysteine: a cross sectional study of Norwegian Works on platforms in the North Sea. Eur J Clin Nutr. 1998;52(1):7-11.

8. Tewari CP, Zhang B, Bluestein IB. Analytical and clinical evaluation of the Bayer ADVIA Centaur ${ }^{\circledR}$ homocysteine assay. Clin Chim Acta. 2004;342:171-8.

9. Neves LB, Macedo DM, Lopes AC. Homocisteína. J Bras Patol Med Lab. 2004;40(5):311-20.
10. Tuschl K, Bodamer AO, Erwa W, Muhl A. Rapid analysis of total plasma homocysteine by tandem mass spectrometry. Clin Chim Acta. 2005;351(12):139-41

11. Refsum H, Ueland PM, Nygard O, Vollset SE. Homocysteine and cardiovascular disease. Ann Rev Med. 1998;49:31-62.

12. Laet C, Wautrecht JC, Brasseur D, Dramaix M, Boeynaems MJ, Decuyper J, et al. Plasma Homocysteine concentrations in a Belgian school - age population. Am J Clin Nutr.1999;69(5):968-72.

13. Pfeiffer MC, Osterloh DJ, Stephenson KM, Yetley AE, Rader IJ, Johnson LC. Trends in Circulating Concentrations of Total Homocysteine among US Adolescents and adults: Findings from the 1991-1994 and 1999-2004. National Health and Nutrition Examination Surveys. Clin Chem. 2008;54(5): 801-13.

14. Stauffenberg TM, Lange AR, Hillis DL. Hyperhomocysteinemia Measured by Imunoassay. Arch Pathol Lab Med. 2004;128(11):1263-6. 